CuPAUAM. 19-1992, 265-288

\title{
UNA COLECCION DE LUCERNAS PROCEDENTE DE HERRERA DE PISUERGA (PALENCIA)
}

ANGEL MORILLO CERDAN

DePTo. PREHISTORIA Y ARQUEOLOGIA

UNIVERSIDAD AUTONOMA DE MADRID

\section{Resumen}

El estudio de los materiales arqueologicos procedentes de las excavaciones de Herrera de Pisuerga ha definido a grandes rasgos el marco tipológico y cronológico de la lucernaria romana en dicho yacimiento. La publicación de colecciones descontextualizadas como la que aquí presentamos tiene como objetivo aportar nuevos datos a este panorama, parte esencial de la vida económica del asentamiento de la Legio IIII Macedonica.

\section{Summary}

The Study of the archaeologic materials proceeding from the Excavations of Herrera de Pisuerga (Palencia) has defined with broad Strokes the chronological and typological Frame of roman Lamps in that Settlement. The publication of collections without archaeological context as that which now present here intents to provide new Information of this Area, essential Part of the economical Life of the Legio IIII Macedonica establisment.

Las lucernas constituyen un documento arqueológico de excepcional interés en cualquier yacimiento de época romana gracias a la valiosa información cronológica y comercial que nos ofrece. En nuestro pais las publicaciones sobre este tipo de material alcanzan un número considerable aunque, en la mayoría de los casos, la atención se ha centrado en su vertiente museística, esto es, en el valor intrínseco de la pieza, en detrimento de su papel como fósil de referencia estratigráfica. En las últimas décadas la aparición de algunos estudios aislados (Clariana i Roig, 1976; Arxe, 1982), que abordan el análisis de las lucernas con un criterio inequívocamente arqueológico, abre nuevas perspectivas en este sentido, más acordes con las actuales tendencias en la investigación fuera de nuestras fronteras (Alarćáo y Da Ponte, 1976; Berges, 1989, entre otros).

El subsuelo de la localidad palentina de Herrera de Pisuerga, la antigua Pisoraca, resulta especialmente rico en restos de época romana. La relación directa que existe entre este hecho y el 
asentamiento en Herrera de la Legio IIII Macedonica durante los reinados de Augusto y Tiberio ya ha sido perfectamente demostrada (Pérez González, 1989; Morillo, 1992; Morillo, 1992 b). Las excavaciones arqueológicas, que se vienen realizando sistemáticamente en dicho yacimiento desde hace diez años bajo la dirección del Dr. D. Cesáreo Pérez González y de D. Emilio Illarregui, han puesto de manifiesto la existencia de un sorprendente conjunto de materiales de todo tipo, entre los que las lucernas constituyen uno de los capítulos principales. A este enorme volumen de material hemos de sumar el que, procedente de hallazgos más o menos fortuitos realizados en el mismo casco urbano y en las tierras de los alrededores, forma parte de las colecciones de vecinos de la localidad que, generosamente, lo han puesto a nuestra disposición.

Presentamos aquí un conjunto de 23 lucernas pertenecientes a varias colecciones particulares de Herrera. A pesar de su estado fragmentario constituyen un elenco bastante completo y representativo de la vida económica de este asentamiento romano. A nuestro juicio, resulta necesario dar a conocer este material, a pesar de las indudables limitaciones que, desde el punto de vista interpretativo, implica su descontextualización arqueológica. En un momento como el actual, en que la investigación contempla con marcado interés las síntesis de carácter general y los análisis de conjunto, puede parecer fuera de lugar el dar a conocer materiales aislados y carentes de indicación estratigráfica. Sin embargo, la existencia de un reciente estudio sobre las lucernas de Herrera de Pisuerga documentadas durante las excavaciones arqueológicas permite imbricar perfectamente las piezas aisladas dentro del marco general del desarrollo y evolución de la lucerna romana en la antigua Pisoraca (Morillo, 1992). Por otra parte, ya en ocasiones anteriores hemos dado buena prueba de nuestro interés en publicar todo tipo de materiales descontextualizados procedentes del yacimiento de Herrera (Morillo y Pérez González, 1990). La información complementaria que pueden aportar sobre aspectos aún no bien aclarados por las excavaciones arqueológicas justifica, a nuestro entender, esta intención.

A continuación presentamos el catálogo de lucernas, ordenado en varios grupos siguiendo criterios cronológicos suficientemente contrastados y aceptados de forma generalizada por los investigadores.

\section{CATALOGO}

A la hora de catalogar cualquier conjunto de lucernas debemos abordar en primer término la elección de una clasificación adecuada. Sin embargo, esta decisión no resulta sencilla, habida cuenta de la proliferación de tipologías en la investigación lucernaria. No deseamos hacer excesivo hincapié en esta cuestión, por otra parte recientemente abordada en un trabajo donde proponiamos adoptar una denominación unitaria para cada forma a partir de las clasificaciones de lucernas más completas y difundidas -las de Dressel, Loeschcke y Deneauve- (Morillo, 1990). Las características cronológicas del conjunto de materiales que aquí presentamos nos han llevado a prescindir de la clasificación de Deneauve, empleando exclusivamente las de Dressel y Loeschcke. Debo señalar, por último, que he prescindido de clasificar dentro de tipos concretos aquellos fragmentos cuyos rasgos morfológicos no resulten del todo claros, en previsión de posibles errores de interpretación.

\section{LUCERNAS DE “CABEZA DE AVE” (DRESSEL 4)}

1.- (Fig. 1) Fragmento de piquera de lucerna perteneciente a la parte izquierda de la misma. Conserva una de las dos cabezas de ave estilizadas, con el cuello doblado y mirando al exterior, 
que dan nombre al tipo. La transición entre el reborde, estrecho y horizontal, y el disco plano se realiza mediante dos molduras lisas escalonadas, que flanquean una banda estriada radialmente en relieve.

Arcilla de color ocre amarillento y dura, cubierta con engobe anaranjado de excelente calidad, muy bien conservado.

2.- (Fig. 1; lám. I) Fragmento de piquera de lucerna del mismo tipo que la anterior. Conserva asímismo la cabeza de ave de la parte izquierda de la pieza, y restos de las tres molduras continuas lisas que constituían la transción al disco. La moldura interna se prolonga hacia el orificio de iluminación en forma de canal abierto.

Pasta ocre y dura, con restos de engobe anaranjado de escasa consistencia. En la parte inferior del rostrum conserva huellas de quema.

3.- (Fig. 1) Fragmento de piquera y margo de lucerna del tipo de "cabeza de ave". Tan solo la cabeza del lado izquierdo, decorada con incisiones oblicuas, ha llegado hasta nosotros. Cinco molduras escalonadas, tres lisas y tres cordadas alternas, separan el disco del reborde, estrecho, horizontal y también decorado con incisiones oblicuas. Un estrecho canal liso separaba las dos cabezas de ave. En la parte superior de éste se encuentra un pequeño orificio de aireación, atravesado longitudinalmente por la fractura de la pieza. Se conserva una pequeña parte del orificio de iluminación. Procede del sector San Millán. (Morillo, 1992, 19-20)

Pasta amarillenta y dura, cubierta con engobe del mismo tono oscurecido por efecto de la cocción. En torno al orificio de iluminación se observan huellas de combustión.

4.- (Fig. 1) Fragmento de orla y pared del depósito, pertenecientes a una lucerna de "cabeza de ave". La transición entre el disco plano y el reborde estrecho está constituida por cuatro molduras escalonadas, tres lisas y una cuarta -la segunda contando desde el exterior- estriada radialmente.

Pasta ocre y dura, con restos de engobe totalmente ennegrecido por la cocción.

5.- (Fig. 1) Fragmento de orla y piquera de lucerna perteneciente un ejemplar del mismo tipo que los anteriores. Se conserva la cabeza de ave del lado derecho, así como parte del orificio de iluminación, con abundantes huellas de quema causadas por la combustión. La transición entre la orla estrecha y el disco se realiza mediante dos molduras lisas que enmarcan otra estriada radialmente y una banda interna concéntrica y granulada. Fue hallada en las tierras del sector sudoriental de la ciudad.

Arcilla ocre claro muy dura, cubierta con engobe rojizo de excelente calidad, oscurecido por efecto de la cocción. La pieza esta ennegrecida en torno al orificio de iluminación. Los rasgos decorativos se encuentran muy desdibujados, hecho debido, sin duda, al empleo de un molde muy gastado en su fabricación.

6.- (Fig. 1) Pequeño fragmento de orla, separada del disco por tres molduras, dos lisas y una con incisiones oblicuas entre ellas. Pertenece con toda seguridad a un ejemplar del tipo de "cabeza de ave.

Arcilla blanquecina, dura y consistente. En algunas zonas quedan restos de engobe de color achocolatado.

A pesar de que en este conjunto de materiales no presentamos ningún ejemplar completo, los rasgos morfológicos de los seis fragmentos descritos no dejan lugar a dudas sobre su pertenencia al tipo de lucerna de "cabeza de ave". El nombre original, Vogelkopflampen, comúnmente empleado por la investigación, fue acuñado por $\mathrm{S}$. Loeschcke en su publicación sobre las excavaciones del campamento romano de Haltern (Loeschcke, 1909, 203) y ha sido erroneamente tra- 
ducido al español como "lucernas de cabeza de pájaro". Los autores no se han puesto de acuerdo sobre la identificación concreta de la especie de ave, hecho que no supone obstáculo alguno para la caracterización del tipo, cuya principal seña de identidad es la presencia de dicho animal.

Desde un punto de vista morfológico, las lucernas Vogelkopflampen son indiscutiblemente republicanas. La estilización del cuerpo, la forma troncocónica del depósito y la piquera terminada en forma de yunque son algunas características aún muy próximas conceptualmente a la lucerna helenística. El margo es estrecho y horizontal, con un asa anular elevada en la parte posterior. La base es plana y las marcas de taller son poco frecuentes. El disco es plano, sin decoración, y está siempre rodeado de un número indeterminado de molduras lisas u ornamentadas con incisiones radiales o cordadas. Esta variedad decorativa, patente en las lucernas de "cabeza de ave" de Herrera de Pisuerga ya estudiadas (Morillo, 1992, 51-76), queda confirmada e incrementada en los seis ejemplares aquí presentados. Especial interés reviste la pieza número 3 del catálogo, cubierta con una profusa decoración realizada mediante incisiones oblicuas, que adornan no sólo las molduras, como suele ser habitual, sino también la orla y las cabezas de ave.

El rasgo más representativo es, precisamente, la presencia de dos cabezas de ave estilizadas y con el cuello doblado flanqueando el rostrum y delimitando entre ellas un canal. Los precedentes iconográficos de esta representación pueden rastrearse facilmente en lucernas helenísticas de los siglos II y I a. C (Ponsich, 1961, 78, lam. I; Deneauve, 1969, 67-8, lam. XXXIII, entre otros).

El tipo ya fue identificado por $\mathrm{H}$. Dressel, que le asignó el número 4 en su clasificación (Dressel, 1899). Las publicaciones posteriores rara vez han adoptado la forma de estudios específicos. Menzel (Menzel, 1954, 24-5) y, algo más tarde, Haken (Haken, 1958, 29-38) son los primeros en dedicar cierta atención a las lucernas de "cabeza de ave". En 1974 Ricci las incluye en su magnífico estudio sobre las producciones tardorrepublicanas, definiendo por primera vez el marco cronológico de referencia (Ricci, 1974). Pero, sin duda, ha sido Pavolini el que ha ampliado de manera significativa nuestro conocimiento sobre la última forma republicana, especialmente en los aspectos relacionados con las áreas de producción y comercialización, hasta entonces desatendidos por los investigadores (Pavolini, 1981; Pavolini, 1987).

Pavolini ha señalado acertadamente que resulta muy probable un origen centroitálico para las lucernas del tipo Dressel 4 (Pavolini, 1981, 162-3). La concentración de hallazgos en Roma y la región lacial parece apuntar en esta dirección. Desde sus centros de producción italianos se extiende por todo el Mediterráneo Occidental, siguiendo una difusión eminentemente costera. Se documenta en numerosos yacimientos de Italia, Francia, España, Portugal y el Norte de Africa, por lo general situados a poca distancia del litoral. Su amplísima difusión preludia, en cierto manera, la registrada por las lucernas de volutas. En la Península Ibérica las Vogelkopflampen se concentran en la costa catalana, las Islas Baleares y los Valles del Ebro y del Guadalquivir. Nuevos hallazgos, salidos a la luz recientemente, han venido a completar el mapa elaborado hace una década por Pavolini (Morillo, 1992, mapas II y IV; Morillo, 1995 c.p.))

Los ejemplares centroitálicos conviven con cierto número de producciones locales, de las que se han podido identificar al menos cinco. En su mayor parte se trata de talleres militares establecidos en distintos campamentos del limes germánico, cuya finalidad sería el abastecimiento de las tropas acantonadas en los mismos. Este sería el caso de los talleres de Weisenau, Xanten, Neuss y tal vez Haltern. Junto a éstos hemos de mencionar los talleres de Sicilia y de Montans, que obedecen a motivaciones muy diferentes, aún no aclaradas en su totalidad.

Solamente una demanda de carácter militar, del mismo tipo que la existente en los campamentos del limes, puede explicar la abundancia de Vogelkopflampen -testimoniada por los seis 
ejemplares que aquí presentamos y el casi centeno de piezas procedentes de excavación (Morillo, 1992, 64-76)- en un punto tan alejado de las rutas Mediterráneas como Herrera de Pisuerga, situada al pie de la Cordillera Cantábrica (Morillo 1992c; Morillo, 1993). La presencia en esta localidad de la Legio IIII Macedonica, conocida a través de documentos arqueológicos de distinto tipo, constituye la explicación lógica de esta producción cerámica (Pérez González, 1989).

La mayor parte de las evidencias estratigráficas sitúan esta producción en los alrededores del cambio de era. A partir de la seriación de los materiales de Albintimilium (Veintimiglia), Ricci data el desarrollo de las lucernas de "cabeza de ave" entre el 20 a. C. y el 10 d. C. (Ricci, 1974, 205), hitos temporales consagrados por la investigación posterior. Sin embargo, algunos autores han formulado serias dudas sobre los umbrales cronológicos de dicha producción. Gualandi Genito y Di Filippo Ballestrazzi adelantan su fabricación a un momento indeterminado entre el 50/30 a. C. (Gualandi, 1977, 74; Di Filippo Ballestrazzi, 1979, 17). Más interesante para este trabajo es la hipótesis planteada por Menzel (Menzel, 1954, 24) y confirmada en yacimientos tan dispares como Treverís (Goethert-Polaschek, 1985, 13), Ampurias (Arxe, 1982, 72) o Montans (Berges, 1989, 36), consistente en una perduración del tipo hasta finales del reinado de Tiberio. El análisis de los materiales de Herrera de Pisuerga apunta en esta misma dirección, como ya hemos expuesto en otro lugar (Morillo, 1992, 65). Esta referencia cronológica, obtenida en contextos arqueológicos perfectamente constrastados, constituye la única pista sobre la datación de las seis piezas de la forma DRESSEL 4 que estudiamos en este trabajo, cuyo marco de referencia temporal se circunscribe a los reinados de Augusto y Tiberio.

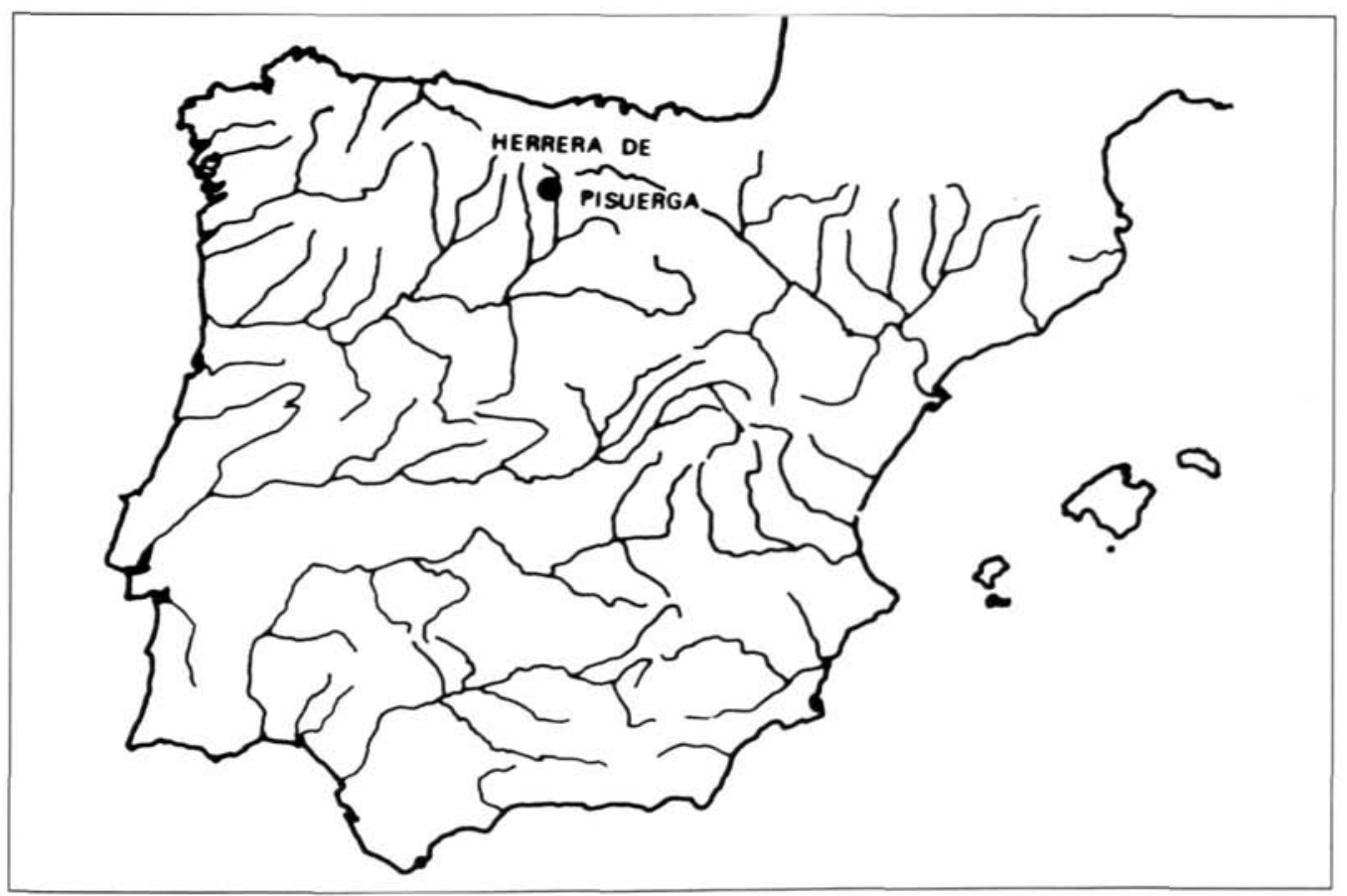

Localización geográfica de Herrera de Pisuerga 


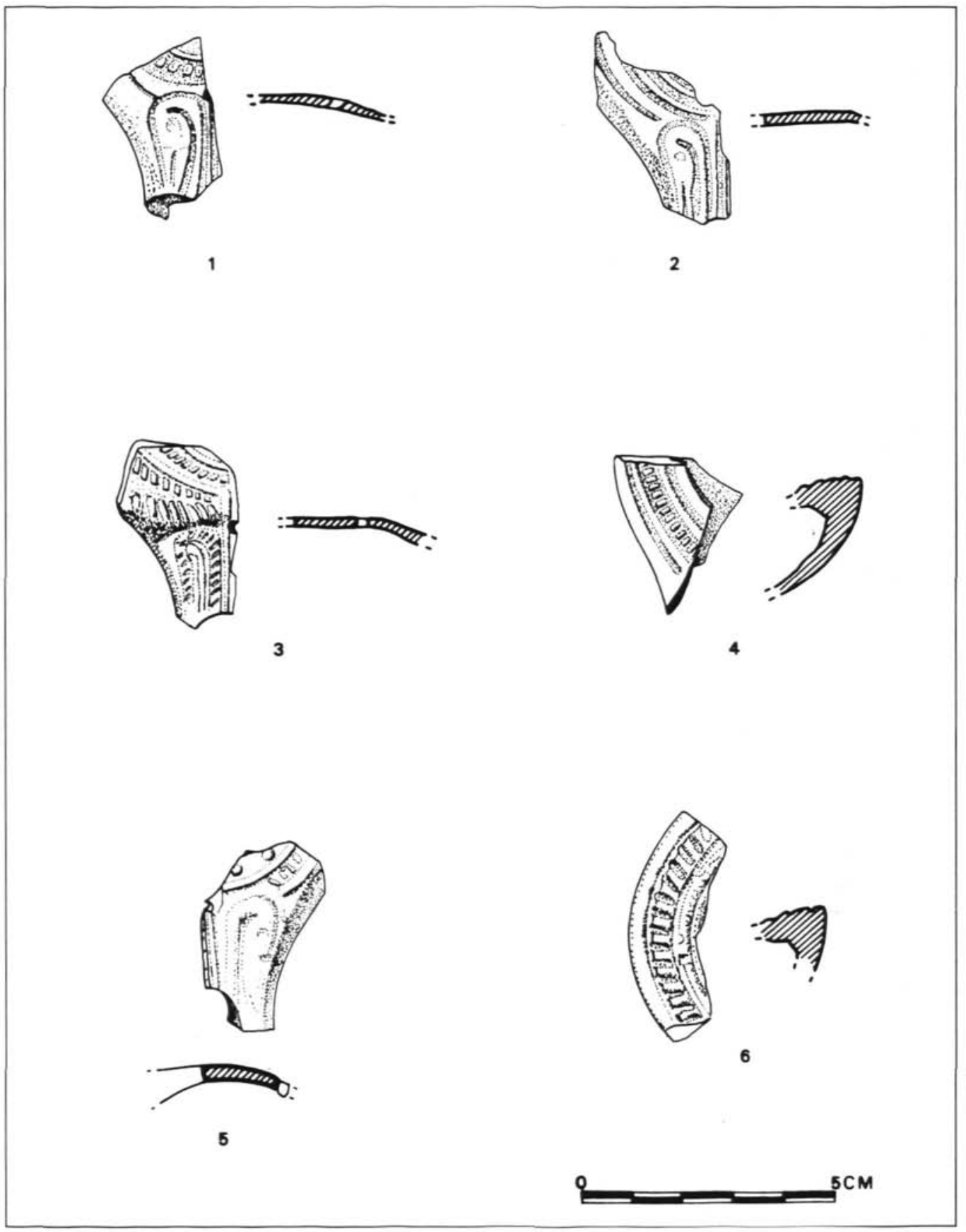

Figura 1 


\section{LUCERNAS DE VOLUTAS}

7.- (Fig. 2) Fragmento de piquera y margo pertenecientes a una lucerna de volutas del tipo Loeschcke IA (Dressel 9). La orla es horizontal y estrecha, separada del disco cóncavo por dos molduras de distinta anchura. Conserva una voluta de arranque del rostrum y algo más de la mitad de éste, en torno al orificio de iluminación, que ha llegado hasta nosotros con huellas de combustión.

Arcilla amarillenta, delgada y dura, muy bien depurada. La pasta estaba cubierta por un engobe acastañado, oscurecido por efecto de la cocción y perdido en algunas partes.

8.- (Fig. 2) Lucerna de volutas completa de la variedad Loeschcke IB (Dressel 9). Sus dimensiones son $104 \mathrm{~mm}$. de longitud, $51 \mathrm{~mm}$. de diámetro del disco y $24 \mathrm{~mm}$. de altura máxima. Presenta una orla estrecha y horizontal, separada del disco por dos molduras de distinto grosor. El disco es cóncavo, ornamentado con la excelente representación de un gladiador tracio en actitud de ataque, con la pierna izquierda adelantada y la derecha hacia atrás, ligeramente flexionada. En su mano derecha empuña el gladius o espada corta, mientras la izquierda, extendida a lo largo del cuerpo, ha dejado caer el escudo rectangular curvo, que se encuentra en el suelo, detrás de la pierna izquierda. El gladiador va vestido con la faldilla corta o subligaculum y el clásico casco tracio con penacho - galea cristata-. El orificio de alimentación, muy descentrado, está situado entre sus piernas.

El rostrum es triangular, del tipo Loeschcke IB.

Entre éste y la orla se abre un pequeño orificio de aireación circular, ligeramente desplazado hacia la izquierda. Las paredes del depósito, bajas y curvas, terminan en una base anular. La pieza carece de asa.

La arcilla es amarillenta y dura, cubierta con engobe anaranjado de excelente calidad, muy bien conservado. En torno al orificio de iluminación, se observan huellas de combustión orgánica. La escena decorativa representada en esta pieza se ha identificado en varios repertorios de lucernas. Los dos ejemplares de Vindonissa (Loeschcke, 1919, 184, n 143, lam. X; Leibundgut, 1977, 165, no 190, lam. 39), así como los procedentes del Agora de Atenas (Perlzweig, 1961, 75, no 40, lam. 2) y del Museo de Aquileia (Di Filippo Ballestrazzi, 1988, 259, no 717, lam. 113) constituyen paralelos iconográficos perfectos. Este parece ser el mismo caso de un fragmento de disco guardado en el Museo de Mérida (Gil Farrés, 1947-8, 115, n 69, lam. V), hasta el momento único testimonio de dicha representación en nuestro pais. Por otra parte, en ejemplares de la misma forma de Berlín, Suiza, Milán, Bonn, Colonia y Treverís, se ha documentado el empleo de este motivo decorativo formando parte de una composición más compleja (Goethert-Polaschek, 1985, 224), lo que viene a confirmar el empleo de punzones parciales en la fabricación de matrices o moldes.

No podemos detenernos aquí en el amplio desarrollo que alcanzaron las representaciones gladiatorias en la lucernaria romana, apenas igualado en otros campos de las artes plásticas. Las escenas de munera sobre lucernas de volutas son muy numerosas durante la primera mitad del siglo I d. C. Se reproducen figuras de gladiadores de todo tipo, aislados o en parejas, en actitudes correspondientes a distintos momentos del combate. En algunas ocasiones incluso se inscriben sobre el disco los nombres de los contendientes. Esta variedad iconográfica constituye buena prueba de la popularidad que alcanzaron los espectáculos gladiatorios en la sociedad romana. Tan sólo el ejemplar publicado en 1977 por Leibundgut (Leibundgut, 1977, 165, nº 190, lam. 39) ha proporcionado información desde el punto de vista morfológico. Su forma - 

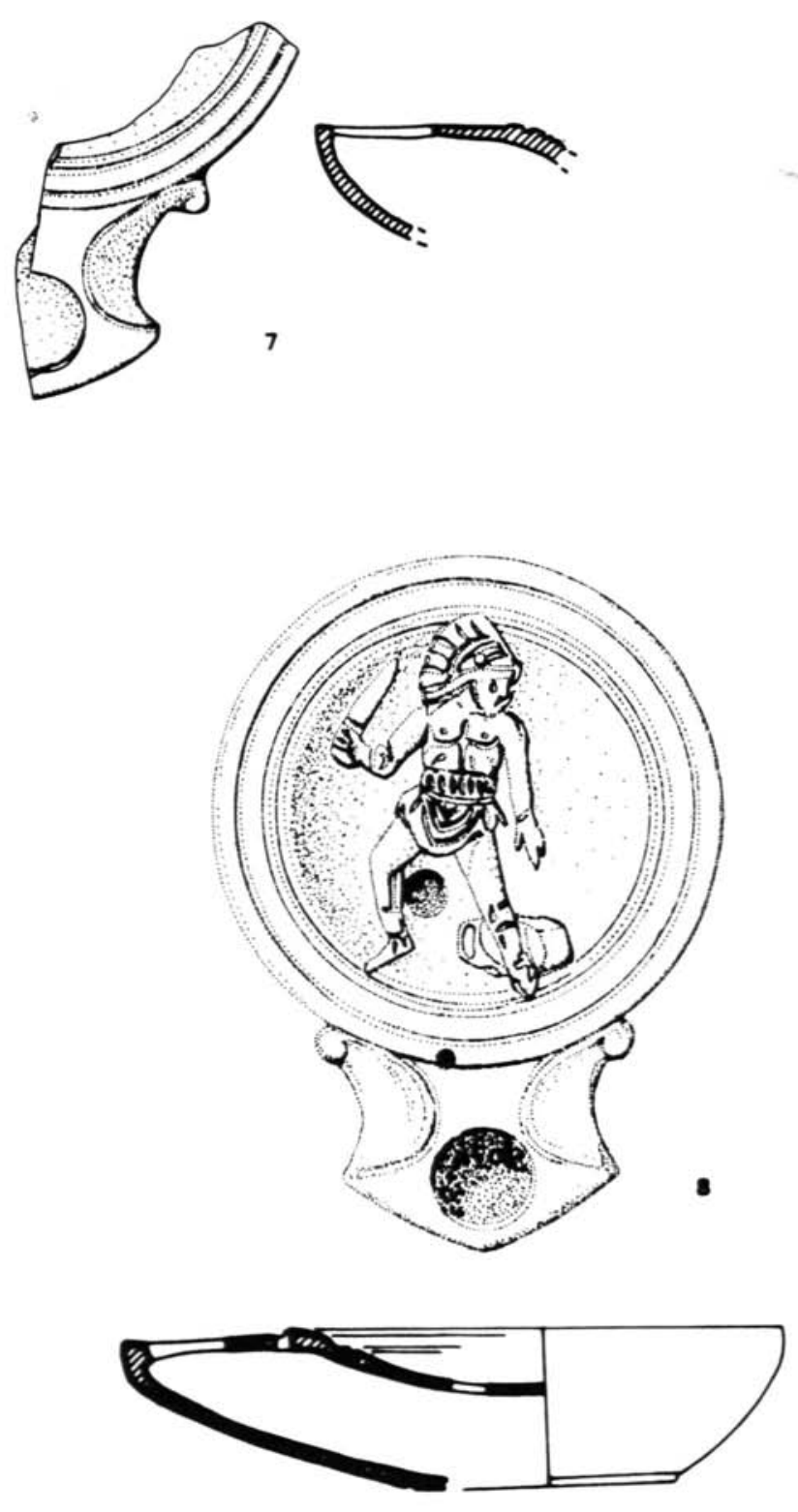

\section{Figura 2}


Loeschcke IB- coincide exactamente con la del ejemplar de Herrera de Pisuerga que aquí presentamos. Otras características secundarias como el color de la arcilla y del engobe, o la disposición de las molduras y el orificio de alimentación en torno al disco resultan identicas en Herrera y en las lucernas de Vindonissa y el Agora ateniense, las que han llegado hasta nosotros en mejor estado. Esta semejanza tan estrecha entre los ejemplares conservados nos lleva a plantearnos su procedencia común a partir de un mismo molde o matriz y, tal vez, de un mismo taller. En cualquier caso, la tipología de estas piezas apunta hacia una cronología tiberiana o claudia.

9.- (Fig. 3) Fragmento de orla y voluta de arranque de la piquera, perteneciente a una lucerna de volutas de tipo indeterminado. Dos molduras separan la orla, horizontal y estrecha, del disco. Procede del sector El Castillo. (Morillo, 1992, 19-20)

Pasta anaranjada, muy dura, cubierta con engobe del mismo tono, gran calidad.

10.- (Fig. 3) Fragmento de lucerna de volutas de tipo indeterminado. Se conserva parte de la orla, del disco y de las paredes del depósito. Dos molduras, separadas por profundas incisiones, constituyen la transición entre el margo horizontal y el disco. Este último es muy cóncavo y presenta restos de una representación decorativa en la que puede reconocerse una hoja vegetal. Procede del sector La Chorquilla. (Morillo, 1992, 19-20)

Pasta blanda de color ocre, cubierta con engobe acastañado, oscurecido durante la cocción y bastante perdido.

11.- (Fig. 3) Gran fragmento de lucerna del tipo Loeschcke IV (Dressel 11). Han llegado hasta nosotros parte de la orla, el rostrum y el disco, aunque sus rasgos apenas resultan reconocibles debido al desgaste del molde con el que se fabricó la pieza. Procede de la zona de las Eras, al sureste del núcleo urbano.

La arcilla es anaranjada, muy dura y pesada, y estaba recubierta con engobe del mismo color, ennegrecido por la cocción.

12.- (Fig. 3) Fragmento de la parte izquierda de un asa plástica en forma de creciente lunar, moldurada interiormente de la misma manera. Pertenece e a una lucerna de volutas del tipo Loeschcke III (Dressel 12-13). Procede de la zona del Castillo.

Pasta de color ocre, recubierta exteriormente con engobe anaranjado, practicamente desaparecido. 13.- (Fig. 3) Fragmento de orla y arranque del rostrum de una lucerna de volutas con piquera triangular (Loeschcke I). Se conservan dos molduras de transición entre la orla y el disco.

Pasta blanquecina, algo blanda, con restos de engobe anaranjado.

14.- (Fig. 3) Fragmento de orla y disco de lucerna con restos de representación figurada inidentificable, separados por tres molduras escalonadas. Las paredes del depósito son altas y oblicuas, y descansan sobre una pequeña sección de base anular.

Arcilla de color ocre oscuro, muy dura, oscurecida por efecto de la excesiva cocción, que ha alterado asímismo el color original del engobe, ennegreciéndolo. Sobre la superfie de la pieza se observan numerosas acumulaciones de arcilla, causadas probablemente por el mal estado del molde que se empleo para su fabricación.

La colección procedente de Herrera de Pisuerga que aquí presentamos cuenta con, al menos, 8 ejemplares de volutas. Esta variedad de lucernas constituye la primera producción imperial propiamente dicha. La generalización del uso del molde durante el proceso productivo de la lucerna permite multiplicar rapidamente el número de piezas fabricado en cada taller. El resultado será una difusión sin precedentes de la lucerna por todo el ámbito mediterráneo e incluso en las áreas marginales del Imperio. 

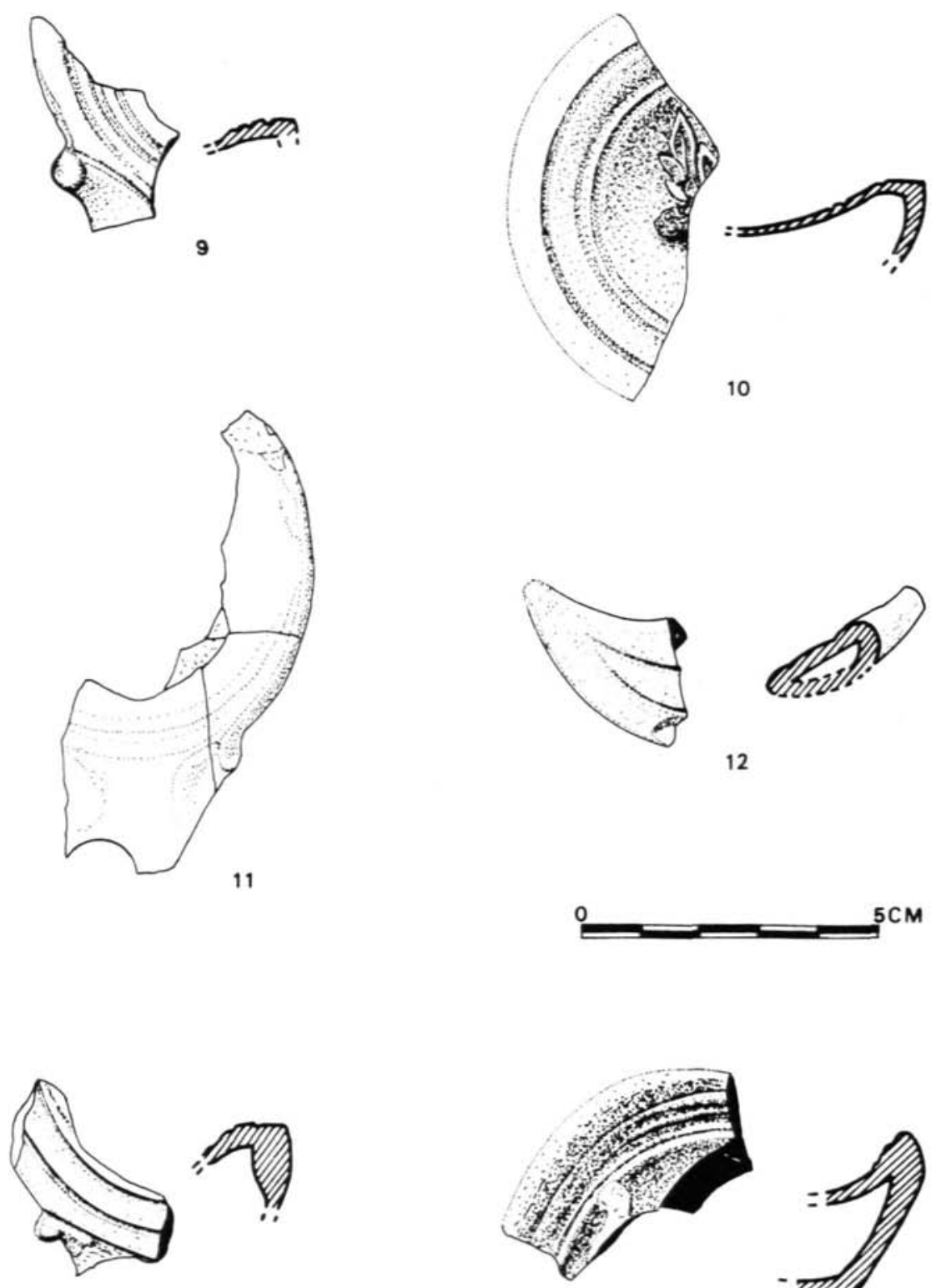

13

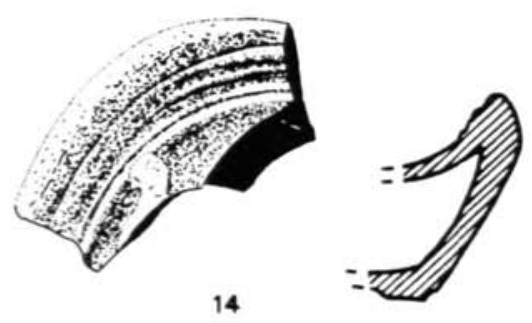

Figura 3 
La morfología registra un cambio radical respecto a la lucerna tardorrepublicana. La utilización del molde permite aprovechar al máximo las posibilidades decorativas del disco, cuyas dimensiones aumentan considerablemente. Su característica formal más representativa, que da nombre la produccion, es la presencia de dos volutas ornamentales en los extremos del arranque del rostrum, fosilización decorativa del punto de unión entre las dos cadenillas de sustentación y el cuerpo en las lucernas metálicas. Se advierten, no obstante, notables diferencias en la configuración de la piquera de las lucernas de volutas, que puede ser triangular o redondeada. Ya en la clasificación de Dressel (Dressel, 1899), se recogían estas dos variantes morfológicas. -Loeschcke definió cinco grupos de lucernas de volutas (Loeschcke I, III, IV, V y VI), de los cuales, el primero correspondía a las lucernas con rostrum apuntado y los restantes a los ejemplares con pico redondeado (Loeschcke, 1919). Los tres subgrupos que establecio Loeschcke dentro de las lucernas con piquera triangular a partir de la relación existente entre la separación de las volutas y de los vértices del pico, han sido aceptados como criterio cronológico válido por la inmensa mayoría de los investigadores posteriores (Loeschcke, 1919, 24-25).

Las excavaciones que se vienen realizando en Herrera de Pisuerga han proporcionado, aunque en cantidades muy diferentes, ejemplares de todas las variedades de lucernas de volutas, a excepción de los tipos más tardíos Loeschcke $\mathrm{V}$ y Loeschcke VI. La forma más común entre los materiales de Herrera es el tipo IA de Loeschcke, con rostrum triangular y volutas muy separadas. Asímismo, ha llegado hasta nosotros cierto número de lucernas con asa plástica (Loeschcke III) y algunos ejemplos aislados de los tipos IB, IC y IV de Loeschcke (Morillo, 1992, 166-7).

De los ejemplares de volutas inéditos que presentamos en esta colección, tan sólo en cuatro casos podemos establecer con certeza la variante tipológica a la que pertenecen, mientras que el resto constituyen fragmentos incompletos de difícil clasificación. Se ha documentado un ejemplar de cada una de las formas Loeschcke IA (pieza $n^{\circ} 8$ ), Loeschcke IB ( $\left.n^{\circ} 7\right)$, Loeschcke III $\left(n^{\circ} 11\right)$ y Loeschcke IV $\left(n^{\circ} 12\right)$. La pieza $n^{\circ} 14$ pertenece al tipo Loeschcke I, aunque desconocemos la variante a la que corresponde. Este conjunto coincide a grandes rasgos con la tipología de lucernas de volutas de Herrera de Pisuerga, establecida a partir de los materiales de excavación (Morillo, 1992, 83-94). Tan sólo el tipo Loeschcke IC, perfectamente identificado en dicho yacimiento, está ausente de la colección que aquí presentamos.

La descontextualización de este conjunto nos priva de evidencias de primera mano sobre la datación de las piezas. En su defecto, debemos tomar como referencia el marco temporal propuesto por el conjunto de los investigadores sobre lucernas para cada forma aunque, en esta ocasión, contamos con la información adicional derivada de las asociaciones estratigráficas en el propio yacimiento de Herrera (Morillo, 1992).

La cronología de las lucernas de volutas es la mejor conocida de todas las lucernas romanas, a pesar de que existen diferencias muy significativas entre uno y otro tipo, de las que aquí no podemos ocuparnos en profundidad y que ya hemos planteado de forma más extensa en otro lugar (Morillo, 1990, 153-57). Loeschcke estableció de forma muy precisa la sucesión temporal de las tres variantes de tipo I, hipótesis que han seguido sin apenas discusión la mayor parte de los investigadores posteriores. La variante IA corresponde a la época de Augusto y Tiberio; el segundo tipo -Loeschcke IB- se data durante el periodo de Tiberio-Claudio; el tercer tipo Loeschcke IC- se desarrolla entre el comienzo del reinado de Nerón y el acceso de Vespasiano al trono (Loeschcke, 1919, 29-30). Por lo que se refiere a las lucernas de piquera redondeada Loeschcke IV-, la investigación sitúa su producción a lo largo del siglo I d. C., aunque el arranque de la misma sin duda tiene lugar antes de mediados de siglo (Morillo, 1990, 154-5). 
Más problemática resulta la adscripción cronológica de las lucernas de volutas con asa plástica o Loeschcke III. La opinión mayoritaria se inclina por un marco temporal contemporáneo al del tipo I de Loeschcke (Ivanyi, 1935, 11-12; Palol, 1948-9, 237 entre otros). Los tipos V y VI, derivados de la forma IV de Loeschcke, fueron datados por este este autor a lo largo de la segunda mitad del siglo I d. C., criterio que se ha mantenido hasta hoy en día sin cambios (Loeschcke, 1919, 33 y 43-5).

$\mathrm{Al}$ margen de algunas matizaciones menores, como el retraso en su aparición de las lucernas con asa plástica hasta el reinado de Tiberio y la datación de los escasas muestras del tipo Loeschcke IV en la segunda mitad del siglo I d. C., el análisis de los materiales de excavación de Herrera no cuestiona el armazón cronológico elaborado por los investigadores para clasificar las lucernas de volutas. Este es, por lo tanto, el marco temporal en el que debemos de situar los ejemplares inéditos de la colección presentada en este estudio.

Ningún dato objetivo podemos ofrecer sobre el lugar de fabricación de los 8 ejemplares de Herrera. Balil opinaba que el tipo de volutas, probable creación de los talleres minorasiáticos, fue rapidamente adoptado por los alfareros centroitálicos (Balil, 1980, 247). El Lacio y la Campania se convierten en las principales áreas productivas, cuyos centros se concentran en las cercanías de los grandes puertos comerciales. Las lucernas itálicas, de excepcional calidad técnica y artística inundaron rapidamente los mercados de la Urbe y las provincias. Sin embargo, a partir del reinado de Tiberio, se asiste a una floración de talleres e imitaciones locales, cuya existencia está impulsada por el desarrollo de la técnica de sobremolde, que simplificaba enormemente el proceso de la fabricación lucernaria. A estos hay que añadir los talleres "itálicos" establecidos fuera de esta provincia ya durante el principado de Augusto, destinados a cubrir las necesidades militares en áreas periféricas. Uno de estos talleres estaría funcionando en Herrera de Pisuerga durante la estancia de la Legio IIII Macedonica, como han venido a demostrar las excavaciones arqueológicas (Morillo, 1992, 167-8). Aunque podemos suponer que la mayor parte de los 8 ejemplares de volutas aquí presentados han sido fabricados en Herrera, carecemos de datos objetivos sobre la procedencia de los mismos.

\section{LUCERNAS DE CANAL O FIRMALAMPEN}

15.- (Fig. 4; lam. I) Lucerna casi completa del tipo Loeschcke IX. Posee $80 \mathrm{~mm}$. de longitud, 50 $\mathrm{mm}$. de diámetro de orla y disco y $28 \mathrm{~mm}$. de altura máxima. Orla redondeada, ancha y levemente inclinada hacia el exterior, con una protuberancia rectangular en el lado derecho dispuesta radialmente, a la que, con toda probabilidad, correspondería otra en el lado contrario, que no ha llegado hasta nosotros. Una alta moldura separa el margo del disco, plano y con el orificio de alimentación descentrado. Rostrum estrecho y alargado, terminado en forma ojival, con el extremo en resalte. Un pequeño canal longitudinal cerrado separa el orificio de iluminación de la moldura que rodea el disco. El depósito es de paredes altas y curvas y en la base, anular, se conserva parte de una marca de taller incisa, en la que puede leerse CO...

La arcilla es anaranjada, muy dura, y carece de engobe. La superficie de la pieza adopta una tonalidad rosada por efecto de la cocción. En torno al orificio de iluminación se conservan huellas de quema.

Las Firmalampen o "lucernas de fábrica" constituyen un grupo bastante bien definido dentro de las lucernas imperiales. Tal denominación, atribuida por Fishbach en 1896 (Fishbach, 1896, 11) venía determinada por las peculiaridades productivas que implicaba su simplicidad formal, 


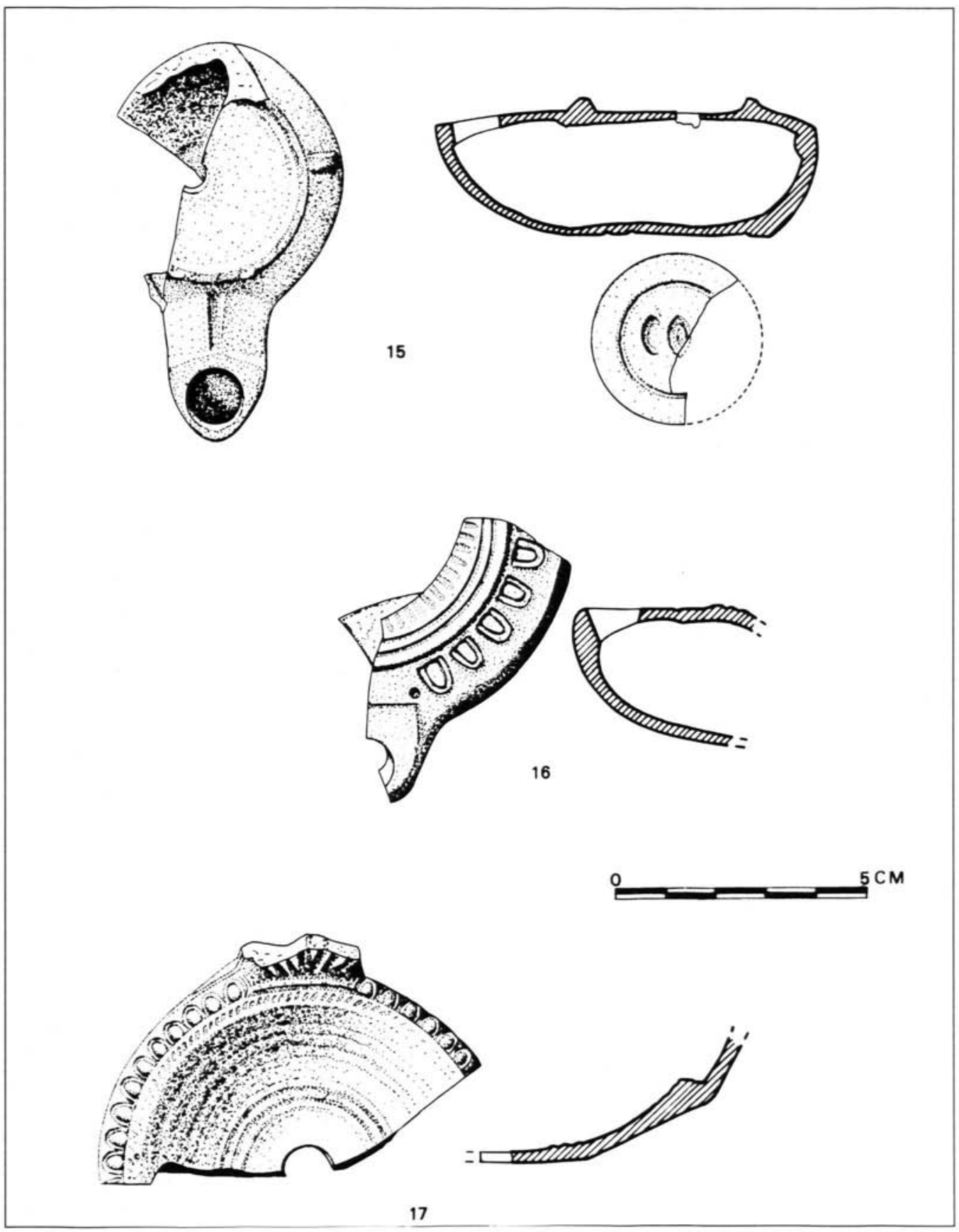

Figura 4 
orientada hacia la fabricación en serie, y a bajo coste, de grandes cantidades de piezas destinadas a la exportación.

La variedad morfológica de las lucernas de canal, nombre con el que suelen aparecer en la bibliografía española, es mucho más reducida que la de otros tipos de lucernas. Resulta un grupo bastante homogéneo en el que se advierte un inconfundible "aire de familia". En general, las diferencias se han establecido a partir de la configuración específica de la alta moldura que rodea el disco. Dressel (Dressel, 1899) incluyó tan sólo uno de los dos grupos principales de Firmalampen - la variante con canal abierto - en su tipología, asignándole diferente nomenclatura en razón de la longitud de la piquera -Dressel 5 y Dressel 6-. Algunos años más tarde, Loeschcke identifica en Vindonissa la variante con canal cerrado, a la que denomina Loeschcke IX (Loeschcke, 1919, 67-9).

Las diferencias desde el punto de vista morfológico tienen su correspondencia en el campo de la cronología. La mayoría de los autores está de acuerdo en que el tipo con canal cerrado es una variedad anterior a las lucernas con canal abierto. Loeschcke situó el marco temporal de su forma IX en el último cuarto del siglo I d. C. (Loeschcke, 1919, 81), aunque algunos autores han adelantado el arranque de su producción en los talleres de la llanura padana hacia el $60 \mathrm{~d}$. C. (De Palol, 1948-9, 239). Loeschcke data la aparición de las variantes de canal abierto o Loeschcke X (Dressel 5 y 6) también en época Flavia, aunque su momento de apogeo tiene lugar en el siglo II (Loeschcke, 1919, 81), hipótesis confirmada por los investigadores posteriores (Morillo, 1990, 160).

Por lo que se refiere al yacimiento de Herrera de Pisuerga, hasta el momento sólo ha proporcionado lucernas de las variedades de canal abierto, asociadas en la estratigrafía a materiales del siglo II d. C. (Morillo, 1992, 98-9). La pieza que aquí presentamos constituye el primer ejemplar del tipo Loeschcke IX documentada en la localidad palentina. Su hallazgo fuera de todo contexto arqueológico restringe nuestras posibilidades de datación al marco general establecido para este tipo de piezas, esto es, el último cuarto del siglo I d. C. No obstante, las peculiaridades morfológicas de esta pieza, de la que no se han hallado paralelos idénticos en los repertorios de lucernas consultados, nos obliga a tomar con cierta prevención esta datación. Ejemplares semejantes, aunque no iguales, se encuentran entre las producciones de la oficina FORTIS de los museos de Treviso (Zaccaria, 1980, 88 y 108, $\mathrm{n}^{\circ} 180$ ) y Aquileia (Buchi, 1975, 73-77, $\mathrm{n}^{\circ} 406,411,435,436$, 445, 446, 447 y 451, lam. XXIII-XXV). También entre las piezas firmadas por CommUNIs de esta última colección (Buchi, 1975, 30-1, n 145, 149, 150, 152, 153 y 155, lam. X y XI). Di Vita publicó en 1950 una lucerna de MYRO bastante parecida (Di Vita, 1950, 201, lam. LVIII).

Al margen de que la fragmentariedad de la marca de taller impide su lectura completa, ni siquiera las dos primeras letras $\mathrm{CO} . .$. han podido ser identificada en los repertorios de lucernas de fábrica. Desconocemos si es una abreviatura de algún alfarero ya bien conocido -como COMMUNIS-, o hace referencia a alguna oficina nueva. Por otra parte, la grafía de la marca y su impresión en negativo, no resulta muy frecuente entre los ejemplares de este tipo.

La manifiesta imposibilidad de identificar la firma de alfarero hace aún más difícil la elaboración de cualquier hipótesis sobre la procedencia de esta pieza. El origen y el centro nervioso de la fabricación de las lucernas de canal es el Valle del Pó. En esta región debieron existir oficinas de un tamaño y volumen de producción más que considerable. Las lucernas noritálicas se exportaron en grandes cantidades hacia el limes germano y danubiano, donde fueron rapidamente imitadas. Por lo que se refiere a la Península Ibérica, Balil ya señaló hace algunos años la abundancia de esta variedad de lucernas en el centro y Noroeste de la misma (Balil, 1983, 306), a diferencia de la costa 
mediterránea y los valles del Ebro y Guadalquivir, donde predominan las lucernas de disco. Este mismo autor ha planteado la posibilidad de imitaciones de Firmalampen en ciertas regiones peninsulares (Balil, 1982, 100). Hasta el momento, esta hipótesis no ha tenido una constatación arqueológica adecuada, aunque hallazgos como los de Herrera vienen a abundar en la cuestión.

\section{LUCERNAS DE DISCO}

16.- (Fig. 4) Fragmento de lucerna de disco del tipo Dressel 20. Conserva parte de la orla, el disco y el rostrum. Este último es redondeado, separado del cuerpo de la lucerna por un surco horizontal y dos pequeños trazos oblicuos, con una pequeña incisión circular sobre cada uno de los vértices. La orla es ancha, ligeramente inclinada hacia el exterior y decorada con una hilera de ovas. Dos molduras gruesas separan la margo del disco cóncavo, de cuya decoración sólo resta parte de una ancha banda radiada. Las paredes del depósito son muy curvas.

Pasta anaranjada, y dura, cubierta con engobe de color rojo vivo, del que sólo quedan restos aislados. En torno al orifico de iluminación se observan restos de combustión.

17.- (Fig. 4; lam. II) Fragmento de disco y orla pertenecientes a una lucerna de la variedad de disco. El diámetro de la pieza es de unos $84 \mathrm{~mm}$. El margo es estrecho, inclinado hacia el exterior y decorado con una hilera continua de pequeñas ovas. De este arranca un apéndice perpencidular semejante a una aleta, decorado con una palmeta vegetal, del que sólo resta la parte anterior. Una moldura cordada y varias más lisas constituyen la transición al disco cóncavo. En torno al orificio de alimentación central se dispone una superficie plana, rodeada por tres molduras. La ausencia de resto alguno de piquera y la peculiar morfología de esta pieza impiden identificar la forma concreta a la que pertenece.

La pasta es ocre, muy dura, y está cubierta con un engobe acastañado, perdido en algunas zonas. 18.- (Fig. 5) Fragmento de piquera, margo y disco perteneciente a una lucerna de disco del tipo Loeschcke VIII L1. El diámetro conjunto de la orla y el disco es de $65 \mathrm{~mm}$. El margo es ancho, inclinado hacia el exterior y separado del disco por medio de dos molduras lisas. Este es cóncavo, con orificio de iluminación central y sin decoración. Entre el disco y la piquera se abría un pequeño orificio de aireación circular, en el momento actual roto y deformado. El rostrum arranca la orla de la lucerna, separados tan sólo por una incisión horizontal.

La arcilla, bastante blanda, es de color ocre amarillento, y está cubierta con un engobe achocolatado muy untuoso.

19.- (Fig. 5) Pequeña sección de orla ancha e inclinada hacia el exterior, perteneciente a una lucerna de disco. Se conserva una moldura de transición al disco, así como el extremo izquierdo del arranque de la piquera, separada de la orla por medio de dos surcos, uno horizontal y otro oblicuo, con una pequeña incisión circular sobre el vértice. Esta morfología corresponde, sin ninguna duda, a un ejemplar del tipo Dressel 20.

La pasta es de color ocre, muy dura. Esta cubierta con engobe acastañado, muy bien conservado. 20.- (Fig. 5) Asa perforada y moldurada exteriormente, perteneciente a una lucerna de disco de tipología indeterminada. Se conserva asímismo una pequeña porción de la orla, ancha e inclinada hacia el exterior, y del disco, con restos de decoración figurada.

La arcilla es blanquecina y dura, cubierta con engobe anaranjado, practicamente desaparecido.

El conjunto de cinco ejemplares que aquí presentamos atestigua una presencia de las lucernas de disco en Herrera de Pisuerga mucho mayor de lo que los resultados de las excavaciones arqueológicas parecían prever (Morillo, 1992, 103-4). Esta denominación, empleada como un 
auténtico cajón de sastre por los investigadores sobre lucernas, engloba distintas producciones de los siglos I al III d. C., todas ellas con parámetros morfológicos muy semejantes e indudablemente emparentadas entre sí. Presentan un cuerpo circular de considerables dimensiones, amplia orla, habitualmente decorada con ovas u otros motivos vegetales, disco frecuentemente decorado y piquera corta y redondeada. El asa es anular, maciza o perforada. A pesar de las semejanzas formales, existen entre ellas diferencias muy significativas desde el punto de vista geográfico y cronológico, aunque la datación de cada tipo dista mucho de estar completamente aclarada. Por otra parte, la proliferación de formas, que adoptan diferente nomenclatura en cada tipología, contribuye a complicar enormemente el estudio de las producciones de disco.

Dressel estableció los tipos principales a partir del estudio de los materiales de Roma (Dressel 1899). Algunos años más tarde, Loeschcke confirma y amplia el número de grupos de lucernas de disco (Loeschcke, 1919, 49-50). El criterio de clasificación empleado por estos autores, aceptado de forma generalizada por sus sucesores, era la forma de unión entre la piquera y la margo. Esta podía ser una simple línea curva incisa (Dressel 17; Loeschcke VIII K), una línea curva cortada con el borde del disco (Dressel 18; Loeschcke VIII K), dos trazos rectos oblicuos (Dressel 19; Loeschcke VIII R), una incisión horizontal y dos trazos oblicuos laterales, con dos puntos incisos sobre los vértices (Dressel 20), una incisión horizontal (Loeschcke VIII L), dos líneas rectas que dejan en el centro un pequeño canal (Dressel 21) o una línea incisa de forma acorazonada (Dressel 27 y 28; Loeschcke VIII H). Habría que añadir además las variantes griegas (Dressel 24 y 25), con piquera separada de la orla con dos trazos rectos oblicuos.

Ya en otro lugar hemos resumido la cronología propuesta para cada tipo, sobre la que no existe unanimidad entre los investigadores (Morillo, 1990, 157-60). Las formas más antiguas arrancan en un momento impreciso situado entre los años finales del reinado de Claudio y el ascenso de Vespasiano al trono (Loeschcke, 1919, 51; Ivanyi, 1935, 13; Bisi Ingrassia, 1977, 8895). Más problemático resulta fijar el límite temporal de las lucernas de disco, sobre el porque parecen existir diferencias regionales muy acusadas (Morillo, 1990, 157-60).

Entre los materiales de excavación hallados en Herrera de Pisuerga, las lucernas de disco constituyen un grupo muy reducido, apenas seis fragmentos, en su mayor parte de forma indeterminada. Hasta el momento habíamos documentado ejemplares de los tipos Dressel 17 (Loeschcke VIII K) y Dressel 20, en niveles arqueológicos correspondientes a finales del siglo I d. C y al siglo II (Morillo, 1992, 104). Los fragmentos que presentamos en este estudio vienen a completar este panorama tan parcial. Añadimos cinco piezas más pertenecientes a variantes de disco, dos de ellas -los números 16 y 19- de la variante Dressel 20, ya atestiguada en la localidad palentina, y una tercera - el $\mathrm{n}^{\circ} 18$ - del tipo Loeschcke VIII L1, inédito hasta el momento.

Sobre la cronología de estos ejemplares, aparecidos fuera de todo contexto arqueológico, tan sólo podemos remitirnos a la datación propuesta para estos tipos en las distintas publicaciones de lucernas. Deneauve, seguido por la mayor parte de los autores, propone una datación entre el 50 y el 150 d. C. tanto para la Dressel 20 como para la Loeschcke VIII L (Deneauve, 1969, 165). Este debe ser, por lo tanto, el marco temporal en el que debemos encuadrar las lucernas de Herrera estudiadas en este trabajo, coincidente, por otro lado, con las observaciones disponibles sobre las lucernas de disco en este yacimiento.

En nuestro estudio sobre las lucernas de Herrera señalabamos que, casi con total certeza, las lucernas de disco constituían una producción importada (Morillo, 1992, 104). Sin embargo, resulta mucho más difícil precisar la región de procedencia de las mismas. Al margen de donde tuviera su origen el tipo, cuestión sobre la que los autores no se ponen de acuerdo, el centro 
neurálgico de la fabricación de lucernas de disco fue el Norte de Africa, concretamente la Provincia Proconsular, desde donde conquistan los mercados mediterráneos, antes dominados por las producciones centroitálicas (Pavolini, 1981, 171-6). Según este mismo autor las lucernas de disco itálicas se circunscriben al área tirrénica y a puntos aislados de Gallia e Hispania (Pavolini, 1981, 176). Sin embargo, el desarrollo del sistema de sucursales y la imitación de moldes con firma de alfarero ha imposibilitado hasta el momento la identificación entre productores itálicos y africanos. Este hecho plantea interrogantes de problemática solución, especialmente en regiones como la Península Ibérica, donde confluyen ambas producciones. A esto hay que añadir la posibilidad de imitaciones locales que compliquen aún más este panorama (entre otros: Amaré, 1987 b, 53 y 61; Rigaud de Sousa, 1965-8, 169).

En nuestro país, las lucenas de disco se concentran a lo largo de la costa mediterránea y en la región meridional, aunque también se han documentado en la Submeseta Norte, siempre en cantidades menores. El conjunto de Herrera es uno de los más numerosos entre los publicados hasta el momento en la mitad septentrional de la Península.

\section{FRAGMENTOS DE FORMA INDETERMINADA}

21.- (Fig. 5) Fragmento de disco cóncavo de lucerna decorado con un symplegma erótico, del que sólo ha llegado hasta nosotros una pequeña parte, aunque la escena ha podido ser reconstruida a través de los paralelos iconográficos publicados. Se representa una pareja sobre un lecho. El hombre, tumbado boca arriba se incorpora apoyándose sobre un codo, levanta el brazo izquierdo hacia la mujer y presenta la cabeza vuelta hacia la derecha. Sobre él se dispone la mujer, también hacia la derecha, aunque vuelve la cabeza mirando a su compañero. Sus brazos están levantados y en cada mano lleva unos crótalos. Los personajes están completamente desnudos, a excepción de una banda de tela, que oculta los pechos de la mujer. Algunos investigadores interpretan esta representación en sentido burlesco, identificando a los personajes como dos enanos. En este ejemplar tan sólo ha llegado hasta nosotros la parte superior de la figura femenina y el extremo de la mano izquierda del varón, habiéndose perdido el resto de la escena. La pasta es ocre, muy fina y dura, y no conserva huellas de engobe.

Las representaciones eróticas, muy populares en la sociedad romana de los primeros siglos del Imperio, gozaron de un espectacular desarrollo en la lucernaria de esta época. Los alfareros dedicados a la fabricación de lucernas tomaron probablemente este tema de otras producciones artísticas -como por ejemplo la terra sigillata italica- y lo incorporaron rapidamente a su repertorio bajo apariencias muy diversas, que componen un repertorio de primer orden sobre las posturas favoritas del ars amandi en el mundo romano.

Entre la gran variedad de escenas eróticas representadas sobre lucernas que han llegado hasta nosotros, la que aquí presentamos, conocida en época clásica como "el caballo de Eros", constituye una de las más comunes. Sus paralelos iconográficos se han podido rastrear en todas las regiones del Imperio. Conocemos ejemplares procedentes de Tarso (Goldman, 1950, 128, n $^{\circ}$ 388, lam. 109), Luni (Ruggiu, 1973-4, 493, C M 2257, lam. 115, 4), el Lacio (Giomi et alii, 1981, 59, no 270), Portorecanati (Mercando, 1974, 207, tumba 27, n 1, fig. 82), Lectoure (Labrousse, 1959, 32, serie V, 4a , lam. 7, 5), Vindonissa (Loeschcke, 1919, 208, no 422, lam. VIII), Nyon (Leibundgut, 1977, 162, $\mathrm{n}^{\circ} 172$, lam. 37), Magdalensberg (Farka, 1977, 318, n $^{\circ}$ 1395, lam. 33) y Treverís (Goethert-Polaschek, 1985, 122-3, no 512, 513, 521, lam. 56). Asímismo se encuentra en las colecciones de los museos de Hungría (Szentleleky, 1969, n 32), 
Maguncia (Menzel, 1954, 45, n 229, lam. 34, 14), Berlín (Heres, 1972, 44, n 192, lam. 24), Chipre (Oziol, 1977, 140, no 395 y 396, lam. 21), Ontario (Hayes, 1980, 49-50, nº 224, lam. 24), Británico (Bailey, 1980, 172, Q 916, lam. 15; 175, Q 924, lam. 16; 227, Q 1079, lam. 37; Bailey, 1988, 157, Q 1496, lam. 1) y la Biblioteca Nacional de París (Hellman, 1987, 37, n 129, lam. XIV). Por lo que se refiere a la Península Ibérica, se ha documentado en el Museo de Lisboa (Ferreira de Almeida, 1952, 153, n 34, lam. XXXI), Conimbriga (Alarcao-Da Ponte, 1976, 97, n 32, lam. XXIV y XXX), Pamplona (Amare, 1987, 30, $n^{\circ}$ 6, fig. 5), Bilbilis (Amare, 1982, 41, nº 28, lam. III) y Valencia (Lerma, 1988, 29-30).

En lucernas de Mauretania (Ponsich, 1961, 92, n 158, lam. XV) y el Museo de Bonn (Heres, $1972,38, \mathrm{n}^{\circ} 145$, lam. 19) aparece una variante iconográfica de la escena con la misma figura femenina realizando el acto sexual con un caballo.

La fragmentariedad del ejemplar de Herrera impide llegar a conclusiones objetivas sobre la forma de la lucerna. Sin embargo, el soporte de los paralelos iconográficos suele ser, en la inmensa mayoría de las ocasiones, la forma Loeschcke IV. Esta coincidencia proporciona alguna pistas sobre la tipología de la lucerna herrerense.

22.- (Fig. 5; lam. II) Pequeño fragmento de disco de lucerna con restos de una escena decorativa. Se conserva tan sólo un torso masculino desnudo de frente, con los brazos abiertos y extendidos. Trás él, y a su derecha, observamos parte de los cuartos traseros y la cola de un cuadrúpedo. Procede del sector del Castillo.

La arcilla es ocre, dura y bien depurada, con restos de engobe acastañado.

Recientemente, Amaré identificaba dos fragmentos con este mismo motivo decorativo, procedentes de Bilbilis, como la posible representación inédita de un Dioscuro, señalando que no había localizado paralelo iconográfico alguno para la misma (Amaré, 1988, 74, lam. IX, 15). No obstante, todas las evidencias morfológicas apuntan a que esta escena es la misma que aparece en varios repertorios de lucernas definida como la lucha entre Hércules y el centauro Nessos. Goethert-Polaschek recoge en su catálogo sobre el Museo de Treverís, un ejemplar procedente de esta localidad junto con otros de Xanten, Suiza y la Universidad de Tubinga (Goethert-Polaschek, 1985, 212, no 88, lam. 28). A éstos debemos añadir los dos ejemplares de Bilbilis ya mencionados y un molde con esta misma representación hallado en San Fernando de Cádiz (Corzo, 1981-2, 59, $\mathrm{n}^{\circ} 18$, fig. 3). Nuevas representaciones procedentes de Pollentia (Palanqués, 1992, 56-7, n 392, fig. 14 y lám. XI) y Cañadahonda (Sevilla) (Moreno Jiménez, 1991, 613, motivo 346) han sido dadas a conocer recientemente. Un estudio aún inédito ha contemplado este motivo iconográfico en particular (Bernal, 1993, c.p.)

Hasta el momento, la escena sólo se ha encontrado representada sobre formas Loeschcke IA y IB, lo que parece indicar una cronología augusteo-tiberiana. Este es el único dato disponible para encuadrar el ejemplar de Herrera.

Entre las figuraciones de héroes o semidioses en la lucernaria romana, Hércules es un motivo recurrente. Sin duda alguna, su largo y complejo ciclo mitológico le convierte en un personaje atrayente para la sociedad romana, interés aprovechado por los fabricantes de lucernas para incorporarlo a su repertorio. Conocemos representaciones del semidios en algunos momentos de sus Doce Trabajos como la lucha con la serpiente del Jardín de las Hespérides, la muerte del león de Nemea o el combate con el centauro Nessos, que decora la pieza que aquí presentamos. Esta última, con toda probabilidad, es la más común de las escenas de Hércules.

23.- (Fig. 5) Fragmento de disco de lucerna de forma indeterminada decorado con una representación figurada inidentificable. Podría tratarse de un genio o erote. Carecemos de cualquier 


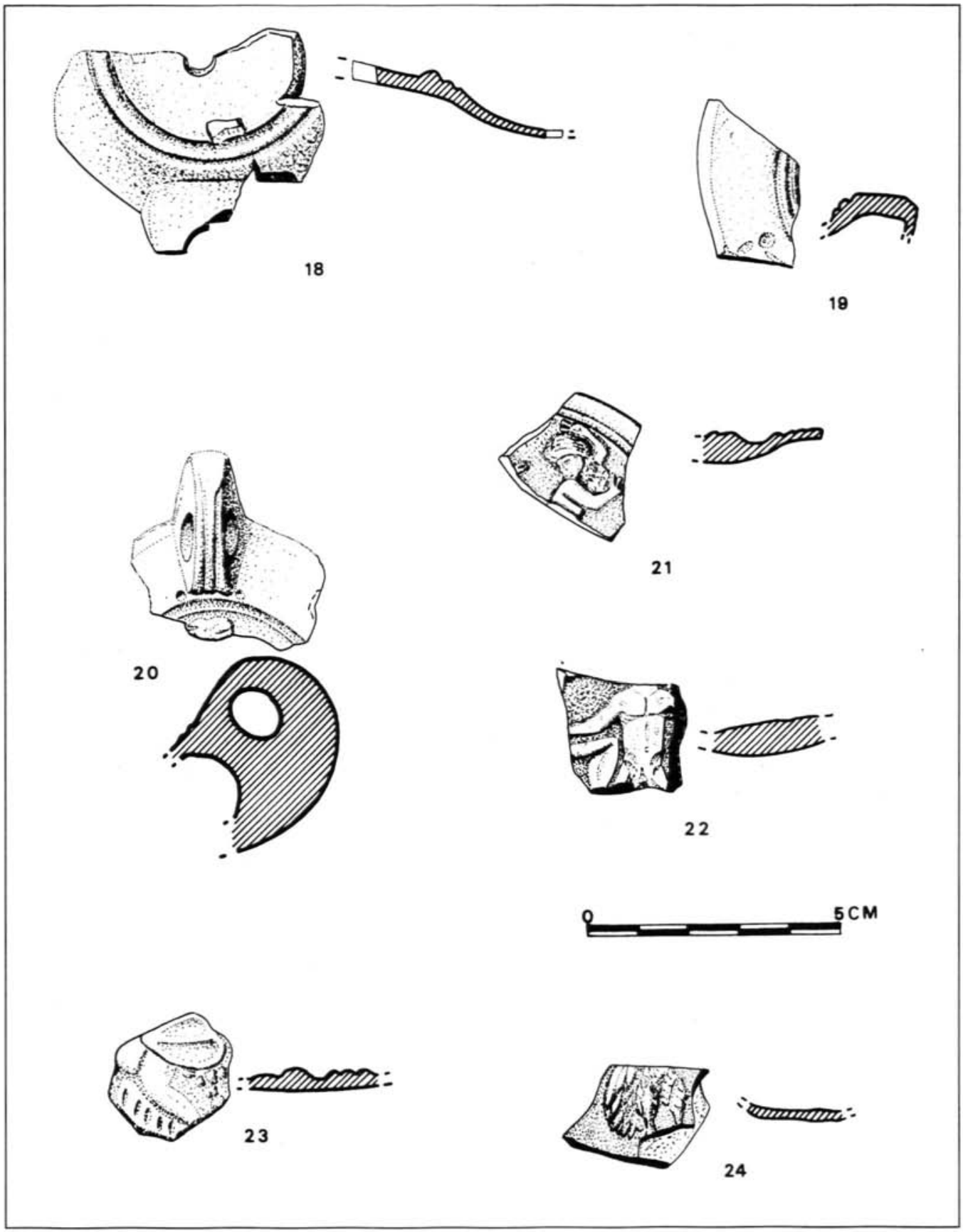

Figura 5 
dato sobre la tipología y cronología de esta pieza. Pasta amarillenta, muy blanda, sin huellas de engobe.

24.- (Fig. 5) Pequeña porción de disco decorado, perteneciente a una lucerna de forma indeterminada. Lo poco que se conserva del motivo ornamental permite identificar un ave posada y con las alas abiertas. Posiblemente se trate de un aguila.

La arcilla es anaranjada, sin huellas de engobe.

El aguila, animal emblemático de Júpiter, aparece representada en numerosas actitudes, aislada o acompañando al Padre de los dioses. El motivo que aquí presentamos parece muy semejante a uno del Museo Británico publicado por Bailey (Bailey, 1980, 228-9, Q 1086, lam. 37), aunque la fragmentariedad del ejemplar impide identificar con exactitud sus paralelos iconográficos. Nada podemos añadir tampoco sobre la tipología de la pieza de Herrera.

\section{ALGUNAS CONSIDERACIONES FINALES}

El conjunto de materiales que aquí presentamos no permite llegar más que a conclusiones a título orientativo sobre la circulación de lucernas en el yacimiento romano de Herrera de Pisuerga. Estas observaciones resultan del todo coherentes, tanto morfológica como cronologicamente, con el análisis de las piezas halladas durante las excavaciones realizadas en dicha localidad palentina, cuyos resultados han sido recientemente publicados. Sin embargo, no dejan de apuntar algunos rasgos novedosos al capítulo de la lucernaria romana en la antigua Pisoraca. Completar, en la medida de nuestras posibilidades, este panorama, ha constituido nuestro objetivo principal al acometer este estudio.

La excepcional riqueza arqueológica de este asentamiento romano, sede de la Legio IIII Macedonica entre el 20/15 a. C. y el 39/40 d. C., ha sido expuesta detenidamente en distintos trabajos. La antigua Pisoraca ha proporcionado uno de los mayores conjuntos de lucernas publicado hasta la fecha en la Península Ibérica, hecho éste que, unido a las características morfológicas de las piezas, resulta una de las principales evidencias de la existencia de un taller local de carácter militar (Morillo, 1992, 167-8).

Las lucernas de "cabeza de ave" y las lucernas de volutas constituyen una mayoría abrumadora en cualquier conjunto de este tipo procedente de Herrera de Pisuerga. Este hecho se repite asímismo en la pequeña colección que aquí estudiamos. Presentamos 6 ejemplares del primer tipo, y 8 de la variedad de volutas, a los que debemos sumar dos fragmentos de discos -los números 21 y 22 del catálogo-, que pertenecen, con toda probabilidad, a este último tipo. Dentro de las lucernas de volutas, se han documentado ejemplares de los tipos Loeschcke IA, Loeschcke IB, Loeschcke III y Loeschcke IV, bien testimoniados entre los materiales de excavación. Por lo que se refiere a las Vogelkopflampen, cuyos rasgos morfológicos en el asentamiento de Herrera de Pisuerga fueron perfectamente definidos en su momento (Morillo, 1992, 51-76), no existe duda posible en cuanto a su identificación.

Por lo que se refiere a la cronología de la piezas aquí presentadas, sólo podemos guiarnos por la datación global asignada a cada tipo por los investigadores sobre lucernas y su reflejo en las estratigrafías de Herrera (Morillo, 1992). En este yacimiento las formas Dressel 4 y Loeschcke IA aparecen siempre asociadas en los estratos augusteos y tiberianos. Por el contrario, las lucernas de los tipos Loeschcke IB y Loeschcke III se retrasan hasta la época de Tiberio. Los escasos ejemplares de la variedad Loeschcke IV se datan en el periodo flavio.

Ya en su momento formulabamos la hipótesis de que futuros hallazgos completaran el parcial 
panorama que se podía entrever a partir de mediados del siglo I d. C. (Morillo, 1992, 169). Este conjunto ha venido a rellenar algunas lagunas significativas acerca de la vida económica del yacimiento trás la marcha de la legión, caracterizada por un espectacular descenso del número de lucernas. Contamos con un único ejemplar de la variedad Firmalampen -el no 16 del catálogo-, aunque adquiere una importancia destacada al tratarse de una forma antigua -Loeschcke IX-, hasta el momento no documentada en el yacimiento. Mayor trascendencia reviste el elevado número de lucernas de disco - 5 ejemplares-, que practicamente dobla el número de ejemplares de dicha forma testimoniados hasta el momento. Este hecho, que avala la continuidad de las actividades económicas y del comercio en la segunda mitad del siglo I d. C., nos obliga a plantear ciertas dudas sobre la supuesta brutal caida de los hallazgos de lucernas en la antigua Pisoraca a partir del reinado de Claudio, tal vez menos dramática de lo que parecía en un principio. Por otra parte, pone en cuestión -al menos por lo que se refiere a Herrera y en el estado actual de las investigaciones- la afirmación de Balil en el sentido de un predominio de las lucernas de canal o Firmalampen en las áreas interiores de la Península, frente a una distribución costera de las lucernas de disco (Balil, 1986, 306). Tal división no parece ser demasiado estricta.

Los materiales aquí estudiados no añaden nada nuevo a lo ya conocido acerca de la procedencia de las lucernas. La fabricación de formas Dressel 4, Loeschcke IA y Loeschcke III en el taller militar establecido por la Legio IIII en Herrera de Pisuerga ha quedado suficientemente demostrada (Morillo, 1993). Debemos suponer que la mayor parte de las Vogelkopflampen y de las lucernas de volutas fueron elaboradas en este taller, aunque tenemos dudas fundadas de que éste sea el caso de los ejemplares número 6 y 7, posiblemente de origen itálico. La Firmalampen y las lucernas de disco constituyen producciones importadas, aunque, en el caso de estas últimas, desconocemos si su procedencia es Italia o el Africa Proconsular.

Los ejemplares estudiados incorporan nuevos motivos iconográficos al elenco de los ya conocidos en el yacimiento, aunque repiten temas bien conocidos en los repertorios de lucernas al uso, como son las representaciones de temática erótica o gladiatoria. Especial relevancia reviste, a nuestro entender, la presencia de un fragmento de disco decorado con el combate entre Hércules y el centauro Nessos. Un molde con esta misma variante iconográfica, se ha publicado recientemente en Cádiz (Corzo, 1981-2, 59, $\mathrm{n}^{\circ} 18$ ). Constituye el segundo ejemplo constatado de paralelos iconográficos perfectos entre el pequeño conjunto de Cádiz y el de Herrera, donde ya habiamos documentado un tritón marino idéntico al gaditano (Morillo, 1992, San Millán no 45). En ambos casos se trata de motivos inéditos o poco frecuentes en la lucernaria romana. Este hecho puede deberse a una casualidad, pero tal vez debamos pensar en unas vinculaciones aún no bien definidas.

Debemos señalar, por último, la incorporación de una nueva marca de taller al reducido repertorio de las conocidas en Herrera de Pisuerga. En este caso concreto se trata de una marca inédita, aunque fragmentaria, inscrita sobre un ejemplar de lucerna de canal -el número $16 \mathrm{del}$ catálogo-. Tan sólo pueden leerse las dos primeras letras "C O...". 


\section{BIBLIOGRAFIA}

Alarcāo, A. M. y Da Ponte, S. 1976: "Les lampes", Céramiques diverses et verres, Fouilles de Conimbriga VI, 93-114, Paris.

AMARE, Ma. t. 1982: "Lucernas romanas de Bilbilis", I Encuentro Estudios Bilbilitanos, 33-41, Calatayud.

... 1987: "Aproximación al conocimiento del mundo romano en Navarra: las lucernas", I Congreso General de Historia de Navarra, Rev. Principe de Viana, Anejo 72, 293-305, Pamplona, 1986.

... 1987 b: Lucernas romanas de La Rioja, Instituto de Estudios Riojanos 6, Logroño.

... 1988: Lucernas romanas en Aragón, Zaragoza.

ARXE, J. 1982: Les llànties tardo-republicanes d'Empúries, Barcelona.

BAILEY, D. M. 1980: A Catalogue of the Lamps in the British Museum. II: Roman Lamps made in Italy, London.

... 1988: A Catalogue of the Lamps in the British Museum. II: Roman Provincial Lamps, London.

BALIL, A. 1980: "Revisión de la cronología de algunas lucernas romanas de Ampurias", Colloqui Int. d'Arqueologia de Puigcerdá (Estat actual de la recerca arqueològica a l'istme pirenee. Homenatge al Dr. Miquel Oliva Prat), 247-49, Puigcerdá.

... 1982: "Notas de arqueología palentina: una lucerna romana hallada en Dueñas", Publicaciones Inst. Tello Téllez de Meneses 46, 93-107.

... 1983: "Lucernas romanas de la necrópolis de Palencia con marca de ceramista", Publicaciones Inst. Tello Téllez de Meneses 48, 298-308.

BERGES, G. 1989: Les lampes de Montans (Tarn). Une production céramique des I er et II e siecle ap. J. C.: modes de fabrication, typologie et chronologie, Documents d'Archéologie Française 21, Paris.

BERnAL, D. 1993 (e.p.): "Tecnología de manufactura de lucernas en época romana: dos elementos de fabricación a molde en la Península Ibérica”. European Meeting of Ancient Ceramic. Barcelona.

BISI INGRASSIA, A. M. 1977: "Le lucerne fittili dei nuovi scavi di Ercolano", L'Instrumentum Domesticum di Ercolano e Pompei nella prima etá imperiale, Quaderni di Cultura Materiale 1, 73-104.

BUCHI, E. 1975: Lucerne romane del Museo de Aquileia I. Lucerne romane con marchio di fabbrica, Aquileia.

Clariana I RoIG, F. 1976: "Les llànties de la villa romana de Torre Llauder (Mataró)", Miscellànies Arquèologiques de Mataró i El Maresme I, 41-84, Mataró.

Corzo, R. 1981-2: "El ceramista Caius Iunius Dracus”, Bol. Museo Cádiz 3, 55-60.

Deneauve, J. 1969: Lampes de Carthage, París.

DRESSEL, H. 1899: "Lucernae formae", CIL XV, II, 1 (Inscriptiones Urbis Romae Latinae. Instrumentum Domesticum), lam. III, Berlín.

FARKA, C. 1977: Die römischen Lampen von Magdalensberg, Kärntner Museumschriften 61, Klagenfurt.

Ferreira de Almeida, J. A. 1952: Introducâo ao estudo das lucernas em Portugal, O Arq. Portugues, n. s. II, 5-208.

FISHBach, O. 1896: Romischen Lampen aus Poetovio, Mitteilungen des historischen Vereines für Steirmark XLIV.

Di FilıPPO BALLeSTRAZZI, E. 1979: "Lucerne aquileiesi di età repubblicana e imperiale in terracotta", $\mathrm{La}$ Lucerna aquileiese in terracotta, 7-27, Aquileia.

... 1988: Lucerne del Museo di Aquileia, 2 vols., Aquileia.

GIl. FarRes, O. 1947-48: "Lucernas romanas decoradas del Museo Emeritense", Ampurias 9-10, 97-115.

GIOMI et alii 1981: "Lucerne e salvadanai: le lucerne como esempio di indagine cognoscitiva", Antiqua 6, 11-84. 
GOETHERT-POLASCHEK, K. 1985: Katalog der römischen Lampen des Rheinischen Landesmuseum Trier. Bildlampen und Sonderformen, Triere Grabungen und Forschungen XV, Mainz.

Goldman, H. 1950: "The Lamps", Excavations at Gözlü Kule, Tarsus. I. The Hellenistic and Roman Period, 84-134, lam. 93-113, Princeton.

Gualand, M. C. 1977: Lucerne fittili della Collezioni del Museo Civico Archeologico di Bologna, Fonti per la Storia di Bologna, Cataloghi, 3, Bolonia.

HaKen, R. 1958: Roman Lamps in the Prague National Museum and in other Czechoslovaki Collections, Acta Musei Nationalis Pragae (Serie A: Historia) XII, 1-2, Praga.

HAYES, J. W. 1980: Ancient Lamps in the Royal Ontario Museum: I. Greek and Roman Clay Lamps, Toronto.

Hellman, M. C. 1987: Lampes antiques de la Bibliothèque Nationale. II: Fond général. Lampes pré-romaines et romaines, Paris.

IvanYI, D. 1935: Die Pannonischen Lampen. Eine typologisch-chronologische Übersicht, Dissertationes Pannonicae 2, 2, Budapest.

Labrousse, M. 1959: "Les lampes romaines du Musée de Lectoure”, Bulletin Société Arch. du Gers, 4367.

LEIBUNDGUT, A. 1977: Die Römischen Lampen in der Schweiz, Bern.

Lerma, J. V. 1988: "Lucernas romanas de Valencia”, Rev. Arqueologia 85, 29-35.

LOESCHCKE, S. 1909: Keramische Funde in Haltern, Mitteilungen der Altertumskommision fur Westfalen $\mathrm{V}$, Münster in W.

... 1919: Lampen aus Vindonissa. Ein Beitrag zur Geschichte von Vindonissa und des Antiken Beleuchtungwesens, Zurich.

MenZeL, H. 1954: Antike Lampen in Römisch-Germanischen Zentralmuseum zu Mainz, Mainz.

MerCando, L. 1974: "La necropoli romana di Portorecanati (Macerata)", Notizie Scavi Antichità XXVIII, 142-430.

MORENO JimenEZ, Fca. 1991. Las Lucernas de la Bética

MORILlo, A. 1990: "En torno a la tipología de lucernas romanas: problemas de nomenclatura", CUPAUAM 17, 143-167.

... 1992: Cerámica romana de Herrera de Pisuerga (Palencia, España): las lucernas, Universidad Int. SEK Santiago de Chile.

... 1992 b: Lucernas romanas de Herrera de Pisuerga (Palencia), en Papeles Herrerenses I, 105-8, Palencia.

... 1992c : "La producción de VogelKopflampen de Herrera de Pisuerga (Palencia, España). Un testimonio revelador de la política militar augusta en la Península Ibérica”. Opus XI (e.p.)

.. 1993: "Una producción de Lucernas en la Península Ibérica: el taller militar de Herrera de Pisuerga (Palencia, españa)” Trabalhos de Antropologia e Etnologia 33, 1-2, p. 351-364 (I Conreso de Arquelogía Peninsular, I, Porto 1993).

... 1995 (e.p.): "Las Lucernas del tipo de 'cabeza de ave' (Vogelkopflampen) en la Península Ibérica ". Madrider Mitteilungen 36

Morillo, A. y Perez Gonzalez, C. 1990: "Hallazgos monetarios de Herrera de Pisuerga (Palencia) en colecciones privadas", Actas II Congreso Historia de Palencia I, Palencia, 1989, 443-461.

Ozıol, Th. 1977: Les lampes du Musée de Chypre, Salamine de Chipre I, París.

PALANQUES, Ma L. 1992. Lucernas de Pollentia, Palma de Mallorca

De PALOL, P. 1948-9: "La colección de lucernas romanas de cerámica procedentes de Ampurias en el Museo Arqueológico Provincial de Gerona”, Memorias Museos Arqueológicos Provinciales IX-X, 233-65.

PAvolinI, C. 1981: "Le lucerne nell' Italia romana", Società romana e produzione schiavistica II. Merci, mercati e scambi nel Mediterraneo, 139-184 y 278-88, Bari-Roma. 
... 1987: "Le lucerne romane fra ilIII sec. a C. e il III sec. d. C.” , Ceramiques hellénistiques et romaines 2, 139-165, París.

PerlzWeIG, J. 1961: Lamps of the Roman Period, The Athenian Agora VII, Princeton.

Perez Gonzalez, C. 1989: Cerámica romana de Herrera de Pisuerga (Palencia, España): la Terra Sigillata, Universidad Int. SEK, Santiago de Chile.

PONSICH, M. 1961: Les lampes romaines en terre cuite de la Maurètania Tingitane, Publications du Service des Antiquités du Maroc 15, Rabat.

RICCI, M. 1974: "Per una cronologia delle lucerne tardo-repubblicaine", RSL XXXIX, 2-4, 168-234.

RIGAUD DE SOUSA, J. J. 1965-8: "Acerca dum molde de lucernas" en "Varia", Trabalhos de antropologia e Etnologia XX, 165-172.

RugGiU, A. 1973-4: "Lucerne", Scavi di Luni I. Relazione preliminare della campagna di scavo 1970-1, 482-502, Roma.

SzentLeleky, TH. 1969: Ancient Lamps, Mèlanges d'Archéologie et d'Histoire I, Budapest.

Di VITA, N. 1950: "Nota su due lucerne di età imperiale", Archeologia Classica II, 2, 201-3, lams. LVIIILIX.

ZaCCARIA, A. 1980: Le lucerne fittili del Museo Civico di Treviso, Collezioni e Musei Archeologici del Veneto 13, Roma. 